\title{
Open Switch Fault Effects Analysis in Five-Phase PMSM Designed for Aerospace Application
}

\author{
Mohamed Trabelsi, Eric Semail, Ngac-Ky Nguyen, Fabien Meinguet
}

\begin{abstract}
This paper describes analytical and simulation tools to analyze the effects of Open Switch Fault (OSF) and Open Phase Fault (OPF) on five-phase PMSM designed for aerospace applications. For such applications, the fault tolerance and the reliability of the drive (PMSM and the power converter) are important to take into account for design. The addressed work aims essentially to analyze the dynamic of the measured phase currents in post-fault operation with a real-time fault diagnostic purpose in the VSI. The paper starts with a presentation of the electric drive system structure and its control used in pre-fault and post-fault operation. Then, fault effects analysis (FEA) on the system will be considered. All results are verified analytically and through simulation software using Matlab/Simulator ${ }^{\circledR}$. The theoretical development and the simulation results show that the five-phase PMSM under inverter faults presents typical characteristics which can be used as better input variables for designing a high performance real-time fault diagnostic and classification process.
\end{abstract}

Keywords-five phase PMSM, open switch fault (OSF), open phase fault (OPF), variable speed drives; fault effects analysis (FEA), aerospace safety.

\section{NOMENCLATURE}

Measured phase currents in abcde frame Stator currents in subspace $\alpha \beta$ Stator currents in subspace $x y$ Mechanical rotor speed

MM Main fictitious Machine

SM Secondary fictitious Machine

ZM Homopolar fictitious Machine

PWM Pulse-Width Modulation

VSI Voltage Source Inverter

OSF Open Switch Fault

OFP Open Phase Fault

FEA Fault Effects Analysis

FDI Process Fault Detection and Identification Process

Back-EMFs Back Electromotive Force

TVC Thrust Vector Control

\section{INTRODUCTION}

In aerospace applications, hydraulic actuation systems are more and more replaced by the electromechanical ones due to advantages in terms of easier maintenance [1]-[2]. Classical proposed solutions employ a three phase permanent magnet synchronous machine (PMSM) fed by a VSI and a DC bus or
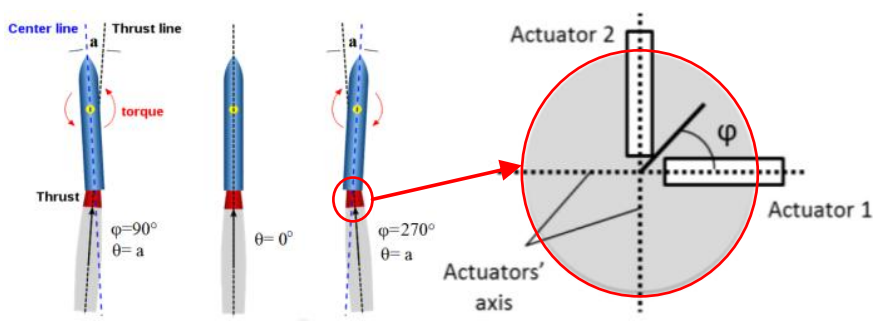

(a)

(b)

Fig. 1 : Considered Thrust Vector Control system (TVC)

(a) Torque generation for 3 inclination cases of the thrust,

(b) Upper view of actuators axis and inclination angle $\boldsymbol{\varphi}$.

a battery. To improve the reliability level, supplementary degrees of freedoms (DoF) are obtained by adding a second parallel standby motor or inverter-legs to the existing ones, and a clutch system allowing switching from one actuator to another [3]-[4]. For the next aerospace generation, a proposed solution consists in replacing the three-phase motors by multiphase ones for higher power density and fault tolerance capability. However, especially in safety critical aerospace applications, these systems should have the ability to support any fault occurred in elementary part of the electromechanical conversion chain, allowing thus the continuous operation of the system.

The considered multiphase machine in this work is a fivephase PMSM studied for use in an aerospace Thrust Vector Control (TVC) system, as shown in Fig.1. The TVC system controls the orientation of the nozzle to define the trajectory of the rocket. The proposed solution is composed of two electromechanical five-phase PMSM which replaces the classical structure based on two hydraulic actuators. More detailed about the general functioning principle are given in [5] and [6] but for six-phase PMSM. Here, the two five-phase PMSM are electrically independent. Each motor uses a fiveleg VSI fed by batteries which replace the hydraulic tank. The minimum functionality of this system, permitting thus the continuous operation under fault condition must be guaranteed.

These aerospace systems are exposed, to hard aerospace environmental and functional conditions inducing faults essentially related to the (VSI). However, even if the multiphase drives are intrinsically fault-tolerant to an opened switch or an opened phase faults since a rotating magnetic field can be still generated, the impact of fault must be carefully studied in terms of oversizing, induced torque ripples 


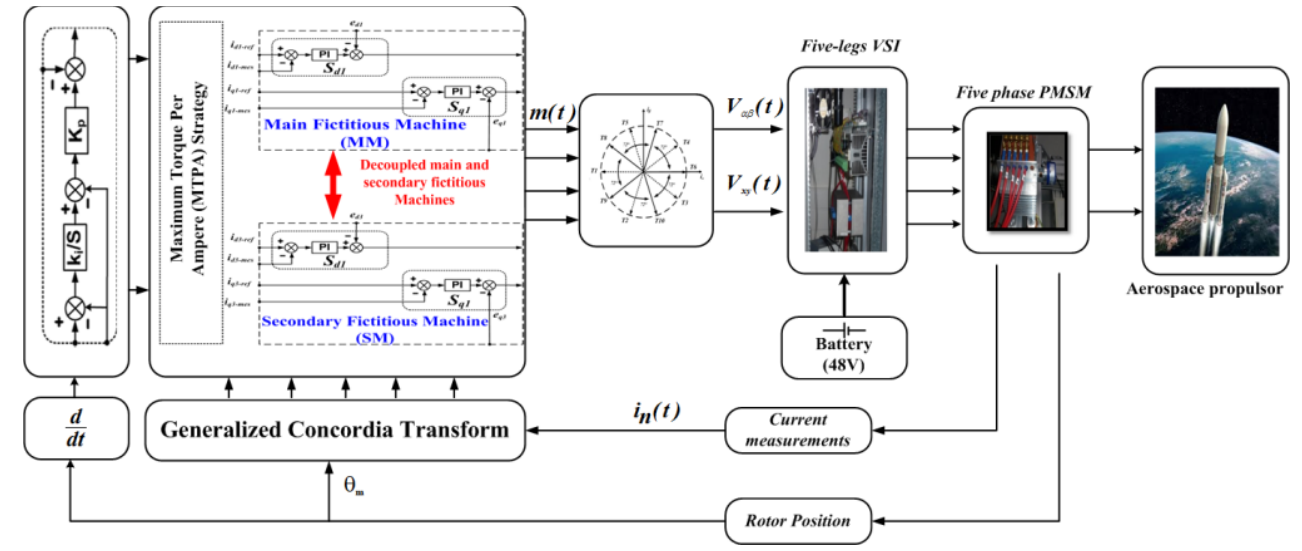

(a) Pre-fault and post-fault control with outer speed control loop and Maximum Torque Per Ampere (MTPA) Strategy

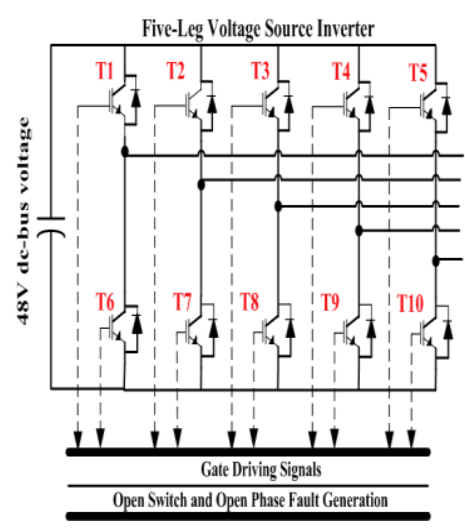

(b) VSI Topology

Fig. 2 : Configuration of the electromechanical conversion chain used in the TVC System

and vibrations that can lead to secondary faults in the other parts of the system [7].

In previously published statistical studies [8], the percentage of faults for three-phase variable-speed drives was evaluated to about $60 \%$ due to the user's experiences during the first year of operation. In addition, $70 \%$ of these faults were related to power switches of the VSI, such as shortcircuit fault and open-circuit fault. The faults considered in this paper are an open switch fault or an open phase fault in the VSI.

The work addressed in this paper aims to contribute with analytical and simulation tools for effects analysis of OSF and OPF occurrence in the VSI feeding five-phase PMSM designed for aerospace applications. After presentation of the electric drive system structure and the used control algorithm, the first contribution of this paper, addressed in section III- A and $\mathrm{B}$, consists in an original formulation of the phase currents under fault conditions. This formulation is based on an additive representation of the faulty currents. The obtained results can be used either to formulate fault-model of the fivephase PMSM or for model-based diagnostic purposes. The second contribution of this work is to show that multiphase PMSM under OSF or OPF presents typical characteristics which can be used as input variables for designing a high performance real-time fault diagnostic process in terms of detectability, resistivity against false alarms, detection time and reduced cost since only the phase current will be needed.

\section{ELECTRIC DRIVE SYSTEM STRUCTURE AND CONTROL}

\section{A. System structure and VSI Topology}

The considered electric drive system is illustrated in Fig.2. It is composed of a DC/AC converter, a five-leg VSI, a fivephase vector-controlled PMSM and a variable load generated through three- phase PMSM.

Regarding the VSI, it is composed by the parallel connection of five legs (Fig.2(b)). It uses a constant voltage source provided through a capacitive dc-link. Each leg features two power switches $\left(\mathrm{T}_{k}, \mathrm{~T}_{k+5}, k=1,2,3,4,5\right)$ with anti-parallel connected freewheeling diodes $\left(\mathrm{D}_{K}, \mathrm{D}_{K+5}\right.$. The VSI is controlled by the gate switching signals $\left(\mathrm{S}_{K}, \mathrm{~S}_{K+5}\right) \in\{0,1\}$. The gate signal $\mathrm{S}_{K}$ or $\mathrm{S}_{K+5}$ is equal to " 1 " when the switch is conducting and equal to " 0 " when the switch is open. Note that $\mathrm{S}_{K}$ and $\mathrm{S}_{K+5}$ must work in a complementary way to prevent the short circuit of the dc-bus voltage and to avoid both switches to be open producing undefined output voltages.

All simulation tests are achieved by using Simulink/Simulator ${ }^{\circledR} /$ SimPowerSystems toolbox. For both normal operating conditions and post-fault operation of the electric drive system, the VSI is modeled with real time model of the power switches considering antiparallel diodes and transistors

\section{B. Pre-fault and Post-Fault Control of the Five phase PMSM}

In this section, the dynamic system of the five-phase PMSM is briefly presented [9]-[16]. However, it is considered, as in most industrial applications, that the neutral point in the star phases of the PMSM is unconnected. As a consequence, there is no path for the homopolar component in the phase currents. However, a two decoupled subspaces with two dimensional (2D) representations can be used to describe and to analyze the five-phase PMSM phenomena under both healthy and faulty operation conditions. Such representation is based on the generalized Concordia Transform defined in (11) and (12) considering the concept of fictitious machines each one being associated to one of the two di-phase characteristic vectorial subspaces of the machine. More details about this theory are given in [9]-[11].

As a result, two decoupled 2D subspaces are defined. The first one is associated with the first harmonic electrical components (voltage, current, back-EMF) corresponding to the Main fictitious Machine (MM) and is noted with index 
$(\alpha \beta)$. The second one is associated with the third harmonic component corresponding to the Secondary fictitious Machine (SM) and is noted with index (xy) (Fig.2 (a)). Here, it should be noted that for more simplicity control of the five-phase PMSM, the Park transformation (two $d q$ rotating frames) is used in addition to the Concordia transformation. In such frames, the currents, the voltages and the flux are constant. Consequently, the control of the two-phase machines can be achieved independently. In these rotating frames, the electrical equations that describe the five phase PMSM are defined by:

- for the fictitious main machine (MM)

$$
\left\{\begin{array}{l}
V_{d m}=R I_{d m}+L_{m} \frac{d I_{d m}}{d t}+e_{d m}-\omega_{m} L_{m} I_{q m} \\
V_{q m}=R I_{q m}+L_{m} \frac{d I_{q m}}{d t}+e_{q m}+\omega_{m} L_{m} I_{d m}
\end{array}\right.
$$

- $\quad$ for the fictitious Secondary machine (SM)

$$
\left\{\begin{array}{l}
V_{d s}=R I_{d s}+L_{s} \frac{d I_{d s}}{d t}+e_{d s}+3 \omega_{m} L_{s} I_{q s} \\
V_{q s}=R I_{q s}+L_{m} \frac{d I_{q s}}{d t}+e_{q s}-3 \omega_{m} L_{s} I_{d s}
\end{array}\right.
$$

where, $\left(\left[v_{d q m}\right],\left[i_{d q m}\right],\left[e_{d q m}\right]\right)$ and $\left(\left[v_{d q s}\right],\left[i_{d q s}\right],\left[e_{d q s}\right]\right)$ are the stator voltages, the phase currents and the backs EMFs linked to the fictitious MM and the fictitious SM, respectively. The five- phase PMSM physical parameters are the resistance $R$ and the equivalent self-inductances $L m$ and $L s$ linked to the MM and SM, respectively. The electrical fundamental pulsation corresponding to the $\mathrm{MM}$, in steady state, $\omega_{\mathrm{m}}$, is given by (3), where $p$ is the pair poles number, $f_{s}$ is the electrical supply frequency and $\theta_{\mathrm{m}}$ is the mechanical rotor position. On the contrary, the electrical pulsation, $\omega_{\mathrm{s}}$, corresponding to the SM, in steady state, is three times higher than $\omega_{\mathrm{m}}$, as given by (4)

$$
\begin{aligned}
& \omega_{m}=p \frac{d \theta_{m}}{d t}=2 \pi f_{S} \\
& \omega_{S}=-3 p \frac{d \theta_{m}}{d t}=-6 \pi f_{S}
\end{aligned}
$$

The developed torque by the five-phase PMSM is the sum of the torque produced by each fictitious machine, which is given by :

$$
\left\{\begin{array}{l}
T_{e m}=\frac{n p}{\omega_{s}}\left(\left[e_{d q m}\right]\left[i_{d q m}\right]^{t}+\left[e_{d q s}\right]\left[i_{d q s}\right]^{t}\right) \\
T_{e m}=T_{m}+T_{s}
\end{array}\right.
$$

Simulated and analytical results, presented in this paper, are obtained without system reconfiguration after fault occurrence. However, the pre-fault control as well as the postfault control is achieved without any change in the control loops (speed and current loops) or in the maximum torque per ampere algorithm (MTPA), shown in Fig.2. The reference
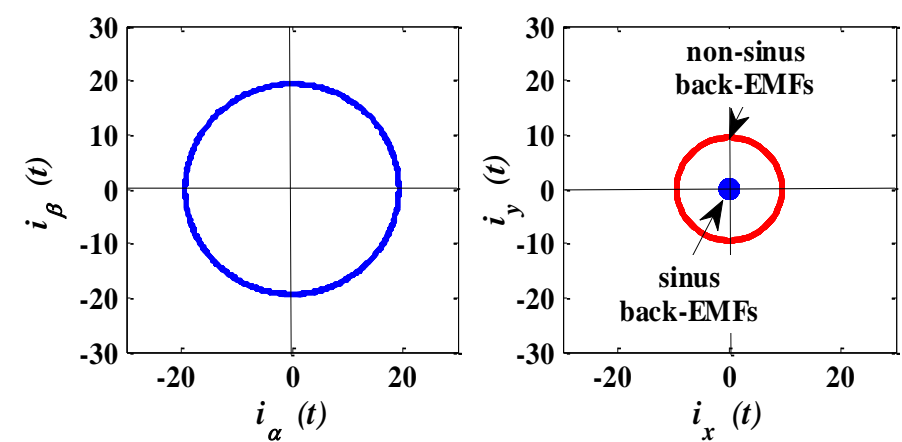

Fig.3: Phase currents waveforms in the decoupled $(\alpha \beta)$ and (xy) subspaces for a healthy condition.

currents $\left(i_{d q-r e f}\right)$ are provided from the outer speed loop and the MTPA strategy.

\section{Phase currents model under healthy condition}

The output currents of the VSI, in the original frame, can be expressed as follows:

$$
i_{n}(t)=\sum_{h=1}^{\infty} I^{h} \sin \left(h\left(p \Omega t-(n-1) \frac{2 \pi}{5}\right)\right)
$$

where, $n=1, \ldots, 5$ represents the phase current $\left(i_{a}, i_{b}, i_{c}, i_{d}\right.$, and $\left.i_{e}\right), h$ is the order of the current harmonics, $I^{h}$ is the magnitude of the hth current harmonic, and $p \Omega$ is the electrical fundamental frequency.

For the PMSM under study, it is assumed that the electromagnetic torque is produced by the low order harmonic components. However, only the first and the third harmonics are considered in this paper. So, the output currents of the VSI given in (6) can be reduced, for a healthy condition, as follows:

$$
i_{n}(t)=I^{h l} \sin \left(p \Omega t-(n-1) \frac{2 \pi}{5}\right)+I^{h 3} \sin \left(3\left(p \Omega t-(n-1) \frac{2 \pi}{5}\right)\right)
$$

The current vector components in the decoupled subspaces $\left(i_{\alpha \beta}\right.$ and $i_{x y}$ ) are obtained by applying the linear Concordia transformation (11) and (12). They are a function of phase currents in the original frame $\left(i_{a}, i_{b}, i_{c}, i_{d}, i_{e}\right)$ as :

- For the first harmonic:

$$
\left[i_{\alpha \beta}\right]=\sqrt{\frac{2}{5}}\left[C_{\alpha \beta}\right]\left[i_{n}\right]
$$

- $\quad$ For the third harmonic:

$$
\left[i_{x y}\right]=\sqrt{\frac{2}{5}}\left[C_{x y}\right]\left[i_{n}\right]
$$

where,

$$
\left[i_{n}\right]=\left[i_{a} i_{b} i_{c} i_{d} i_{e}\right]^{t}
$$




$$
\begin{aligned}
& {\left[\mathrm{C}_{\alpha \beta}\right]=\left[\begin{array}{lllll}
1 & \cos \frac{2 \pi}{5} & \cos \frac{4 \pi}{5} & \cos \frac{6 \pi}{5} & \cos \frac{8 \pi}{5} \\
0 & \sin \frac{2 \pi}{5} & \sin \frac{4 \pi}{5} & \sin \frac{6 \pi}{5} & \sin \frac{8 \pi}{5}
\end{array}\right]} \\
& {\left[C_{x y}\right]=\left[\begin{array}{lllll}
1 & \cos \frac{4 \pi}{5} & \cos \frac{8 \pi}{5} & \cos \frac{12 \pi}{5} & \cos \frac{16 \pi}{5} \\
0 & \sin \frac{4 \pi}{5} & \sin \frac{8 \pi}{5} & \sin \frac{12 \pi}{5} & \sin \frac{16 \pi}{5}
\end{array}\right]}
\end{aligned}
$$

Applying (8) and (9) to (7), the obtained inverter output currents in Concordia frames are expressed by:

$$
i_{\alpha \beta^{(t)}}=\left\{\begin{array}{l}
\sqrt{\frac{5}{2}} I^{h l} \sin (p \Omega t) \\
\sqrt{\frac{5}{2}} I^{h l} \sin \left(p \Omega t+\frac{\pi}{2}\right)
\end{array}\right.
$$

and,

$$
i_{x y}(t)=\left\{\begin{array}{l}
\frac{9}{\sqrt{10}} I^{h 3} \sin (3 p \Omega t) \\
\frac{9}{\sqrt{10}} I^{h 3} \sin \left(3\left(p \Omega t+\frac{\pi}{2}\right)\right)
\end{array}\right.
$$

The simulated results for a healthy inverter are depicted in Fig.3. Under normal conditions, the shapes of the Concordia current components are a circle centered at the origin for the two subspaces $(\alpha \beta)$ and $(x y)$. Here, it is important to underline that for the multiphase machines without the third harmonic (sinusoidal EMFs) or with very low magnitude of the third harmonic, the shape of the phase currents, in Concordia frame corresponding to SM, is a point at the origin of $x y$ plane.

\section{INVERTER FAULTS EFFECTS ANALYSIS ON FIVE PHASE PMSM}

\section{A. Analytical Modelling of OS Fault in the VSI}

In this subsection, the power switch fault modeling is addressed. It aims essentially to provide information about the electric drive system behavior under inverter fault condition. As the phase currents are the only quantities available in the electric drive system, they present an attractive solution to design real time FDI process, increasing, consequently, the global reliability function of the electromechanical conversion chain and system continuity service, as in the demanding aerospace applications.

A way to model the faulty phase currents in original frame, under open power switch in the VSI, consists in using an additive representation, as shown in Fig.4, resulting in the following quantities:

$$
i_{n}^{f}=i_{n}+f_{n}
$$

where, $i_{n}^{f}$ denotes the phase current under fault condition. $i_{n}$ is the phase current $\mathrm{s}$ in normal operation case, and $f_{n}$ is

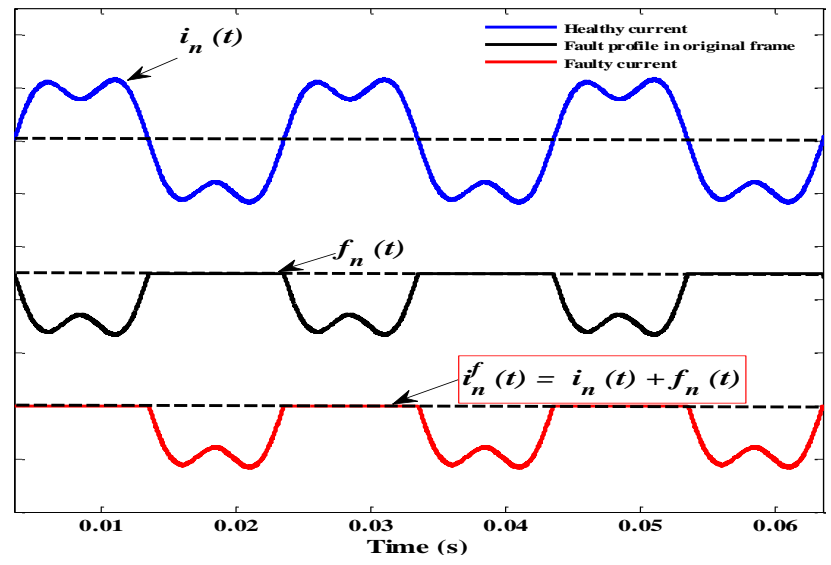

Fig.4. Phase current profile in original frame under fault condition: open-circuit in the upper switch $\mathrm{T}_{\mathrm{k}}$ of phase $n$.

TABLE. I

FAult Profile ACCORdING to the FAUlty Switch

\begin{tabular}{|c||c|c|c|c|c|}
\hline \multirow{2}{*}{$\begin{array}{c}\text { FAULTY } \\
\text { SwITCH } \\
\text { ES }\end{array}$} & \multicolumn{5}{|c|}{ Fault quantities } \\
\hline \hline T1 & $f_{a}$ & $f_{b}$ & $f_{c}$ & $f_{d}$ & $f_{e}$ \\
\hline T6 & $\leq \mathbf{0}$ & & & & \\
\hline T1\&T6 & bidirectional & & & & \\
\hline T2 & & $\leq \mathbf{0}$ & & & \\
\hline T7 & & $\geq \mathbf{0}$ & & & \\
\hline T2\&T7 & & bidirectional & & & \\
\hline T3 & & & $\leq \mathbf{0}$ & & \\
\hline T8 & & & $\geq \mathbf{0}$ & & \\
\hline T3\&T8 & & & bidirectional & & \\
\hline T4 & & & & $\leq \mathbf{0}$ & \\
\hline T9 & & & & $\geq 0$ & \\
\hline T4\&T9 & & & & bidirectional & \\
\hline T5 & & & & & $\leq \mathbf{0}$ \\
\hline T10 & & & & & $\geq 0$ \\
\hline T5\&T10 & & & & & bidirectional \\
\hline
\end{tabular}

the fault quantity corresponding to each phase of the five phase PMSM. This variable can be expressed, according to the fault location in the VSI, by:

- If the OSF occurs in $T_{k}$ :

$$
f_{n k}=\left\{\begin{array}{c}
\left\{\begin{array}{c}
-I^{h l} \sin \left(p \Omega t-(k-l) \frac{2 \pi}{5}\right)-I^{h 3} \sin \left(3\left(p \Omega t-(k-1) \frac{2 \pi}{5}\right)\right) \\
(k-l) \frac{2 \pi}{5} \leq \omega t \leq \frac{\pi}{2}+(k-1) \frac{2 \pi}{5},
\end{array}\right. \\
\left\{\begin{array}{c}
\pi+(k-1) \frac{2 \pi}{5} \leq \omega t \leq 2 \pi+(k-1) \frac{2 \pi}{5}
\end{array}\right.
\end{array}\right.
$$

- If the OSF occurs in $T_{k+5}$ :

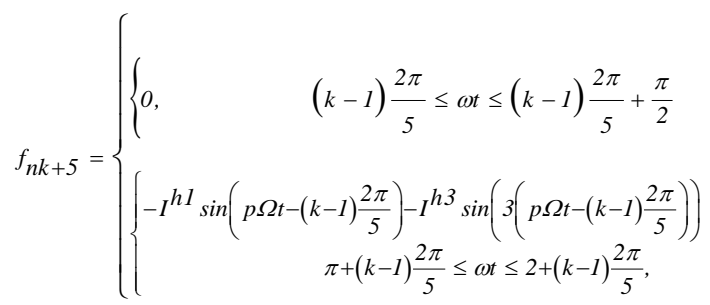


For illustration, let us take an example of an OS fault in the upper switch $T_{\mathrm{k}}$ of the VSI. Shown in Fig.4 is a qualitative representation of the fault profile and the corresponding phase current for this fault scenario. By applying the additive representation defined in (15), the fault profile $f_{n}$ presents a negative direction. As a consequence, the current in phase $n$ is limited to flow only in the negative direction. Similar results can be obtained for an OS fault in the lower power switch. However, if the fault occurs in $\mathrm{T}_{k+5}$, the inverter can no longer synthesize the negative portion of the phase current, and $f_{n}$ will present only a positive direction but during the second relative half period. The sign of the fault profile $f n$ is given in Table.I according to the faulty switch location. Here, it should be noted that for an open phase fault, $f_{n}$ presents both positive and negative directions over a fundamental current period. However, as it exists ten power switches $\left(T_{1} \ldots, T_{10}\right)$ in five-legs VSI, ten fault directions can be defined in the original frame (abcde).

Applying now the linear Concordia transformation, given in (8) and (9), and taking into account the additive representation given in (15), the faulty phase currents are expressed in Concordia frames by:

$$
\left[i_{\alpha \beta x y}^{f}\right]_{\text {Concordia }}=\sqrt{\frac{2}{5}}[C]^{T}\left[i_{n}^{f}(t)\right]
$$

The resulting components in the decoupled subspaces $\alpha \beta$ and $x y$ are expressed as follows:

$$
\left[\begin{array}{c}
i_{\alpha \beta}^{f} \\
i_{x y}^{f}
\end{array}\right]=\left[\begin{array}{c}
i_{\alpha \beta} \\
i_{\alpha \beta}
\end{array}\right]+\left[\begin{array}{l}
f_{\alpha \beta} \\
f_{x y}
\end{array}\right]
$$

with,

$$
\begin{aligned}
f_{\alpha} & =\sqrt{\frac{2}{5}}\left(f_{a}+\cos \left(\frac{2 \pi}{5}\right) f_{b}+\cos \left(\frac{4 \pi}{5}\right) f_{c}+\cos \left(\frac{6 \pi}{5}\right) f_{d}+\cos \left(\frac{8 \pi}{5}\right) f_{e}\right) \\
f_{\beta} & =\sqrt{\frac{2}{5}}\left(\sin \left(\frac{2 \pi}{5}\right) f_{b}+\sin \left(\frac{4 \pi}{5}\right) f_{c}+\sin \left(\frac{6 \pi}{5}\right) f_{d}+\sin \left(\frac{8 \pi}{5}\right) f_{e}\right) \\
f_{x} & =\sqrt{\frac{2}{5}}\left(f_{a}+\cos \left(\frac{4 \pi}{5}\right) f_{b}+\cos \left(\frac{8 \pi}{5}\right) f_{c}+\cos \left(\frac{12 \pi}{5}\right) f_{d}+\cos \left(\frac{16 \pi}{5}\right) f_{e}\right) \\
f_{y} & =\sqrt{\frac{2}{5}}\left(\sin \left(\frac{4 \pi}{5}\right) f_{b}+\sin \left(\frac{8 \pi}{5}\right) f_{c}+\sin \left(\frac{12 \pi}{5}\right) f_{d}+\sin \left(\frac{16 \pi}{5}\right) f_{e}\right)
\end{aligned}
$$

It can be seen, from equations (20) and (21), that the fault profiles in the original abcde-frame are reflected in the decoupled subspaces $\alpha \beta$ and $x y$, maintaining the additive representation defined in (15). However, each fault case in original frame has its equivalent profile in Concordia frames. This property is interesting since it allows to study the fault quantity and the variables quality in such frames when an open switch and/or an open phase occur in the VSI.

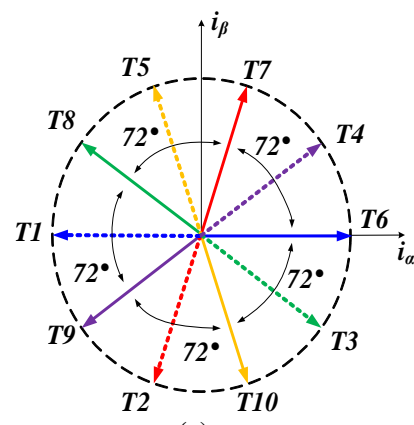

(a)

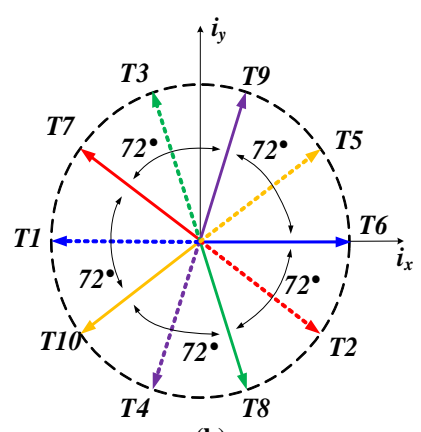

(b)
Fig.5: Typical references in Concordia frame under OSF condition. (a) $\alpha \beta$ frame, (b) $x y$ frame.

As already mentioned in the above section, the main objective is to find interesting informative variables that can be used to design a robust and real-time FDI process. In this paper, we show that the fault profiles quantities expressed in Concordia frames will permit the determination of unique typical references, linked to fault in inverter power switches, derived from (20) and (21) and resulting from the additive representation of the fault profile in original frame (16) and (17) (These assertions are illustrated in the rest of the paper).

The OS FEA is achieved, based on analytical and simulation results. For the analytic results, the subsystems (1) and (2) are rewritten, according to the new fault profiles quantities, as:

- $\quad$ for the fictitious main machine (MM)

$$
\left\{\begin{array}{l}
v_{\alpha}=R\left(i_{\alpha}+f_{\alpha}\right)+L_{m} \frac{d\left(i_{\alpha}+f_{\alpha}\right)}{d t}+e_{\alpha} \\
v_{\beta}=R\left(i_{\beta}+f_{\beta}\right)+L_{m} \frac{d\left(i_{\beta}+f_{\beta}\right)}{d t}+e_{\beta}
\end{array}\right.
$$

- for the fictitious Secondary machine (SM)

$$
\left\{\begin{array}{l}
v_{x}=R\left(i_{x}+f_{x}\right)+L_{S} \frac{d\left(i_{x}+f_{x}\right)}{d t}+e_{x} \\
v_{y}=R\left(i_{y}+f_{y}\right)+L_{S} \frac{d\left(i_{y}+f_{y}\right)}{d t}+e_{y}
\end{array}\right.
$$

The analytical model given in (22) and (23) and the simulation software described in Fig. 2 are used to discuss the OS fault effects on the five-phase PMSM and its contribution in the decoupled Concordia frames.

\section{B. OSF Unique-References in Concordia Frames}

This step is achieved by a direct evaluation of the faulty Concordia current components $i_{\alpha \beta}$ and $i_{x y}$ under fault conditions. It is performed using their average values over a fundamental current period as: 


$$
\begin{aligned}
& \left\langle i_{\alpha \beta}^{f}\right\rangle(t)=\frac{1}{T(t)} \int_{t-T(t)}^{T(t)}\left(i_{\alpha \beta}(t)+f_{\alpha \beta}(t)\right) d t \\
& \left\langle i_{x y}^{f}\right\rangle(t)=\frac{1}{T(t)} \int_{t-T(t)}^{T(t)}\left(i_{x y}(t)+f_{x y}(t)\right) d t
\end{aligned}
$$

Here, it should be noted that, regardless the shape of the back-EMF and independently of the operation conditions of the system, the average values of the current components $i_{\alpha \beta}(t)$ and $i_{x y}(t)$, corresponding to healthy conditions, are always close to zero. So, the expression given in (24) can be rewritten as follows:

$$
\begin{aligned}
& \left\langle i_{\alpha \beta}^{f}\right\rangle(t)=\left\{\begin{array}{l}
M_{i \alpha}=\frac{1}{T(t)} \int_{t-T(t)}^{T(t)} f_{\alpha}(t) d t \\
M_{i \beta}=\frac{1}{T(t)} \int_{t-T(t)}^{T(t)} f_{\beta}(t) d t
\end{array}\right. \\
& \left\langle i_{x y}^{f}\right\rangle(t)=\left\{\begin{array}{l}
M_{i x}=\frac{1}{T(t)} \int_{t-T(t)}^{T(t)} f_{x}(t) d t \\
M_{i y}=\frac{1}{T(t)} \int_{t-T(t)}^{T(t)} f_{y}(t) d t
\end{array}\right.
\end{aligned}
$$

By introducing (20) and (21) in (25), the reference directions under single OS fault for both $\alpha \beta$ frame and $x y$ frame, can be expressed by

$$
\begin{aligned}
& d_{n \alpha \beta-r e f}=\operatorname{atan}\left(\frac{M_{i \alpha}}{M_{i \beta}}\right)=\left\{\begin{array}{l}
\pi+(k-1) \frac{2 \pi}{5}, \text { if } f_{n}(t) \leq 0 \\
(k-1) \frac{2 \pi}{5}, \text { if } f_{n}(t) \geq 0
\end{array}\right. \\
& d_{n x y-r e f}=\operatorname{atan}\left(\frac{M_{i x}}{M_{i y}}\right)=\left\{\begin{array}{l}
\pi-(k-1) \frac{2 \pi}{5}, \text { if } f_{n}(t) \leq 0 \\
-(k-1) \frac{2 \pi}{5}, \text { if } f_{n}(t) \geq 0
\end{array}\right.
\end{aligned}
$$

Fig.5 shows all reference directions according to the faulty switch and 2D subspace.

\section{Analytical and simulation results of OS FEA}

This section presents a summary of the main analytical and simulation results conducted on the simulation software (Fig.2) and on the analytic model of the inverter fault presented in (22) and (23). The parameters of the five-phase PMSM are given in table (1). Two fault modes are investigated: an open switch fault and open phase fault. Other similar tests are carried out to show the third harmonic effect
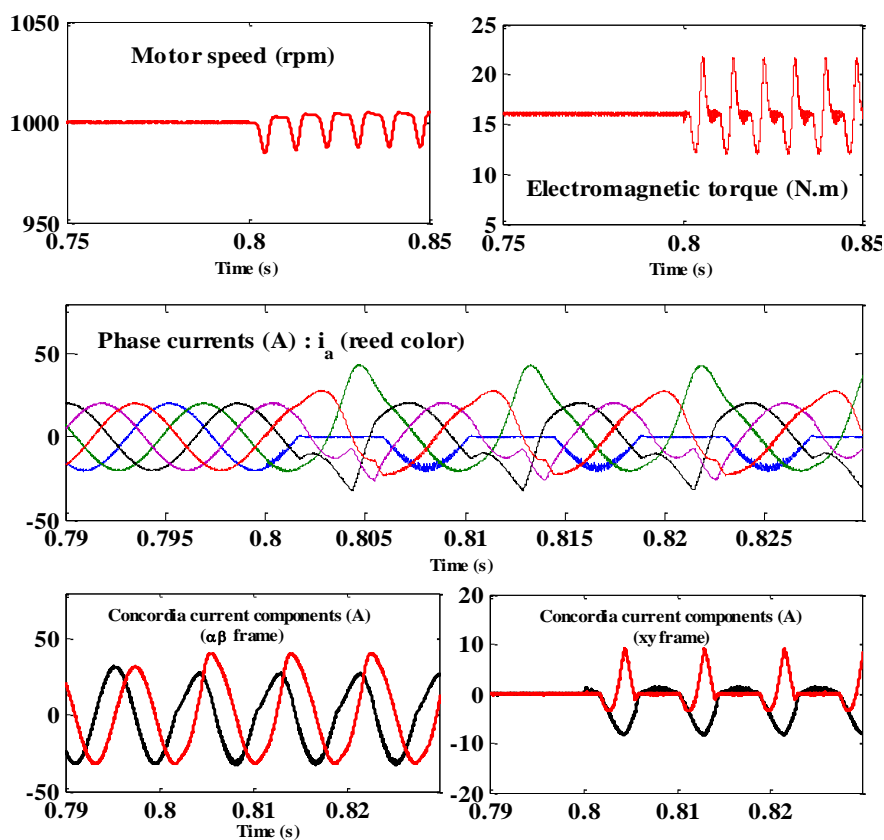

Fig.6 : Obtained results for a healthy inverter and under an open switch fault in the VSI.

Table. I : five phase PMSM parameters

\begin{tabular}{|c|c|c|c|c|c|c|}
\hline $\mathrm{R}(\Omega)$ & $\mathrm{Lm}(\mathrm{H})$ & $\mathrm{Ls}$ & $\mathrm{p}$ & $\mathrm{P}(\mathrm{kW})$ & In-max & dc-bus \\
\hline $9.1 \mathrm{~m} \Omega$ & $3.1 \mathrm{mH}$ & $0.9 \mathrm{mH}$ & 7 & 10.5 & $125 \mathrm{~A}$ & $48 \mathrm{~V}$ \\
\hline
\end{tabular}

on the typical shapes of the phase currents in the Concordia frames under fault condition.

Results under healthy operating conditions and in the case of an open switch fault in the VSI are shown in Fig. 6 which presents, respectively, the time waveforms of the rotor speed, the electromagnetic torque, the phase currents in original frame and their equivalents in the decoupled frame $(\alpha \beta)$ and (xy). The five-phase PMSM speed is set to 1000-rpm with a $15-$ N.m as a load torque.

1) Time waveforms analysis: Firstly, the electric drive system operates free of any fault, the obtained results show good tracking performances of the five-phase PMSM rotor speed, torque and currents. They clearly illustrate the effectiveness of the control loops (speed and current loops) in healthy condition.

The open switch fault is caused in the upper switch T2 of phase $b$ at $t=0.801 \mathrm{~s}$. In this case, the open circuit fault is applied to the upper transistor of the second inverter leg (phase b) during permanent operating mode of the electric drive system. It is observed that the dynamic performances of the system are affected only when the current of the faulty inverter leg is normally positive (because of the open-circuit fault of T2). During the rest of the period when the current becomes negative, the electric drive system performances are similar to the healthy state. Here it should be noted that, although the open circuit fault of T2, the five phase PMSM is still capable to operate but with torque and speed ripples, leading to more stress and thermal cycling in the power 


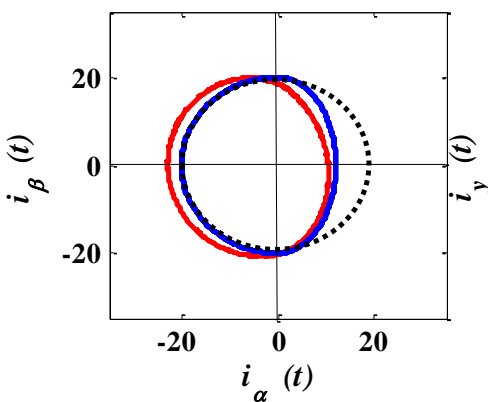

(a) OSF in T1

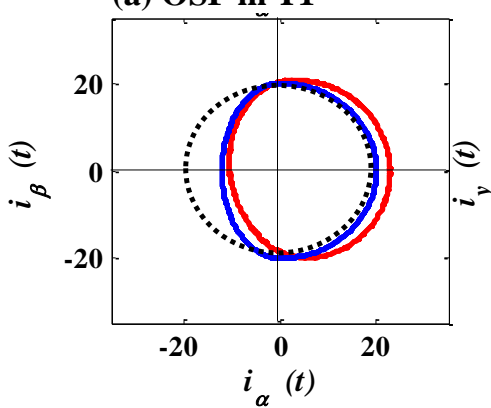

(c) OSF in T6

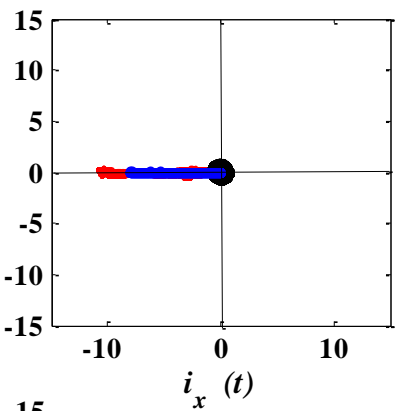

(b) OSF in T1

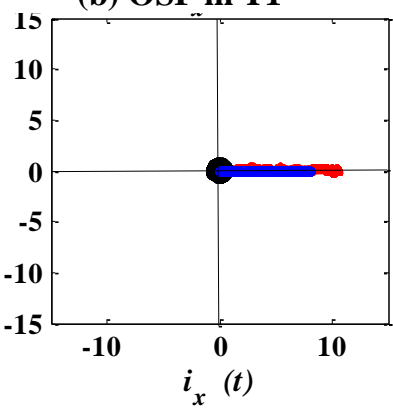

(d) OSF in T6

Fig.7 : Analytical (blue color) and simulated (reed color) results of the OS FEA on five phase PMSM under fault condition. No 3rd harmonic applied by the control.

switches and other functional blocs in the electromechanical conversion chain. Regarding the Concordia current components, the OSF effect results in a light deformation of the $\alpha \beta$ current components. On contrary, the $x y$ current components are more affected by the fault. Here, it is clear that the results obtained under faulty operating conditions confirm and justify those obtained by the theoretical modeling discussed in section III (A) based on the additive representation of the inverter fault.

2) OS FEA in Concordia frames: Analytical and simulated results of the OS FEA are shown in Fig. 7 - 9. Three fault modes are investigated. Firstly, only the 1st harmonic component is applied to the five phase PMSM to produce the torque. For these operating conditions, two fault modes are investigated: single OSF in transistor T1 or T6 (Fig.7), single OSF in transistor T2 or OSF of two transistors in the same inverter leg (an open phase $b$ fault) (Fig.8). The second test consists in applying the 3rd harmonic component together with the 1st harmonic to produce the torque under fault condition. for this fault scenario, two fault modes are investigated : an OSF in transistor $\mathrm{T} 2$ and an OSF in two transistors in the first inverter leg (open phase $a$ fault) (Fig.9). For all tests, the reference speed and the load torque are set to 1000-rpm and 10-Nm, respectively.

As previously mentioned (sectionII-c), for a pre-fault operation conditions, the shape of the phase currents, in $\alpha \beta$ frame, is a circle centered at the origin, and, in the $x y$ frame, the shape is a point at the origin if the 3rd harmonic is not applied to the five-phase PMSM. Regarding now the post-fault operation of the electric drive system under an OSF, Fig.7(a-d) and Fig.8 (a-b), it is expected theoretically and from

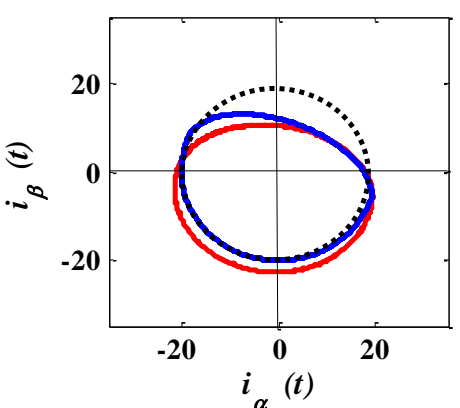

(a) OSF in T2

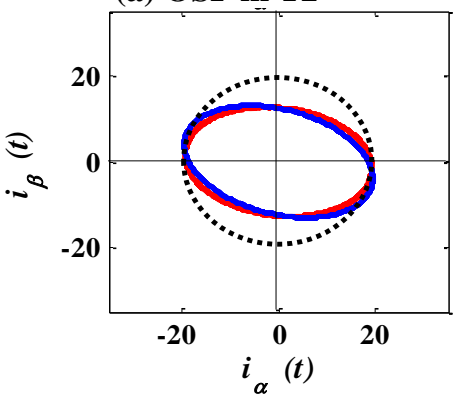

(c) OSF in T2 and T7

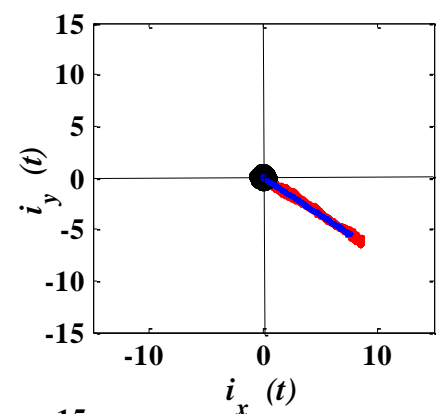

(b) OSF in T2

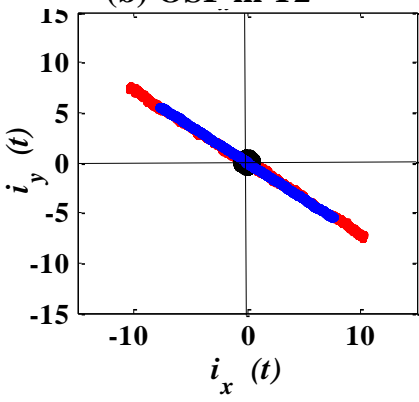

(d) OSF in T2 and T7
Fig.8 : Analytical (blue color) and simulated (reed color) results of the OS FEA on five phase PMSM under fault condition. No 3rd harmonic applied by the control

simulation that the phase current shape in $\alpha \beta$ frame is lightly affected by the fault over a half plane corresponding to the affected alternation of the faulty phase in comparison with the pre-fault operation. Regarding the $x y$ frame, the fault occurrence contributed to the relatively high deformation in such frame. However, it is observed that the fault occurrence results in a high modification of the current trajectory. From these results, it should be noted that the fault occurrence shows typical shapes, in Concordia frames, characterizing the fault nature and location in the VSI.

For illustration, let us take as example the single OS fault in T1, as shown in Fig.7 (a-b). The fault occurrence modifies the phase currents trajectory, in $\alpha \beta$ frame, in a circle with a light deformation in comparison with the healthy condition. This shape is periodic and its position $(-\pi \mathrm{rad})$ is associated to the faulty phase a (transistor T1). With similar reasoning, the fault in T1 shows a typical shape in $x y$ frame with a position equal to $(-\pi \mathrm{rad})$. With the same reasoning, the single OS fault in the other power switches leads to the same shape but with other axis half plane orientation according to the faulty inverter leg. All reference directions are already theoretically computed and given in Fig.5 (a, b) according to the faulty switch.

Regarding the open phase fault case, it is observed, from analytical and simulation results, Fig. 8 (c-d), that the typical shape in $\alpha \beta$ frame results from the intersection of the typical shapes corresponding to the single OSF of the involved transistors (T2 and T7). Contrariwise, the typical shape, in the $x y$ frame, is the sum of that corresponding to the OSF of T2 and T7. 


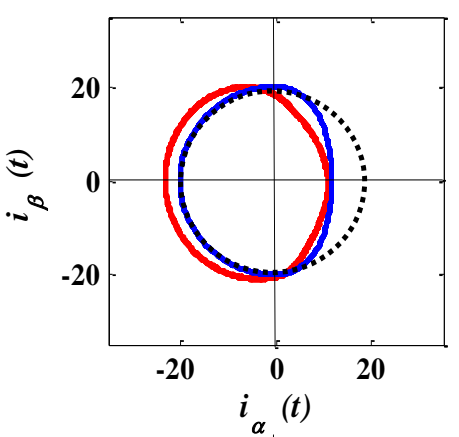

(a) OSF in T1

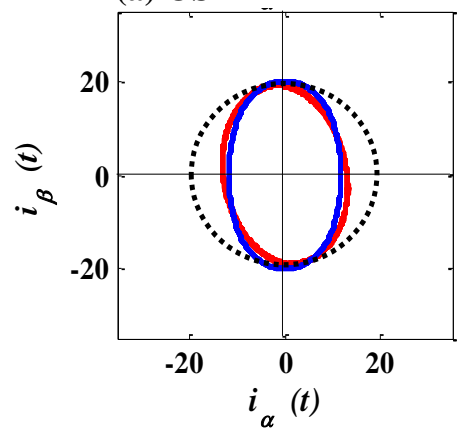

(c) OSF in T1 and T6

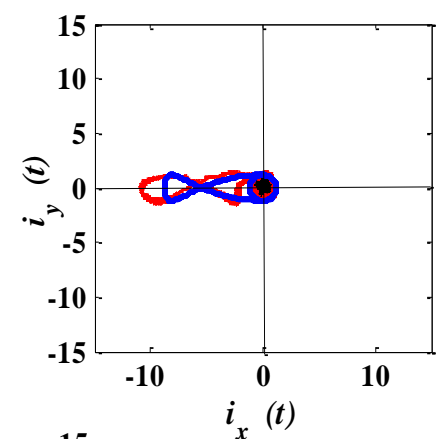

(b) OSF in T1

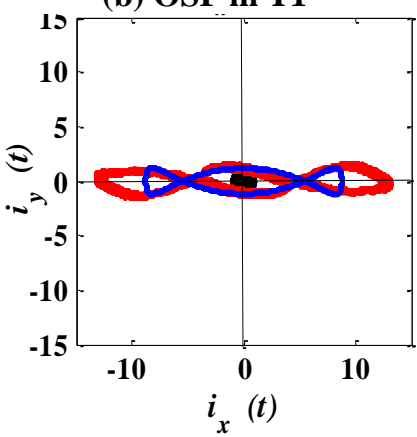

(d) OSF in T1 and T6
Fig.9 : Analytical (blue color) and simulated (reed color) results of the OS FEA on five phase PMSM under fault condition. With 3rd harmonic component applied by the control.

2) 3rd harmonic component effect on the typical shapes: OS FEA results addressed in Fig. 9 are obtained in post-fault operation case of the electric drive system with the third current harmonic component applied to the five phase PMSM. Once more, it is expected analytically and by simulation that the phase currents show typical shapes in $\alpha \beta$ frame and in $x y$ frame in comparison with the healthy operation mode of the electrical drive system. But, in this case, only the typical shape in $x y$ frame is modified by the added harmonic component because the decoupling of the primary and secondary sequence planes. However, there is no modification of the typical shape in $\alpha \beta$ frame. Here, it should be noted that although the current shapes modification by applying the 3rd harmonic component, their reference directions remains the same as without the 3rd harmonic applied since are based on their mean values over a fundamental current period.

\section{CONCLUSIONS}

In new aerospace generations, multiphase drives-based PMSM have an important place because of their faulttolerance capability and high power density. In this paper, we have proposed analytical and simulation tools to analyze the effects of the OSF and OPF on the five-phase PMSM. For this purpose, we have proposed, firstly, an original formulation of the phase currents under fault conditions based on an additive representation of the fault quantity. Then, we have proved that the five-phase PMSM under fault condition presents typical and unique characteristics which can be used for FTC purposes or as input variables to design a high performance real-time fault diagnostic process. The obtained analytical and simulated results will be verified experimentally in the laboratory and will be used for diagnostic an FTC purposes.

\section{REFERENCES}

[1] L. de Lillo, L. Empringham, P. W. Wheeler, S. Khwan-On, C. Gerada, M. N. Othman, X. Huang, "Multiphase power converter drive for faulttolerant machine developpment in aerospace applications," IEEE Trans. Ind. Electron., vol. 57, no.2, pp. 575-583, February 2010.

[2] X. Huan, A. Goodman, C. Gerada, Y. Fang, Lu, "Design of a five-phase brushless dc motor for a safety critical aerospace application," IEEE Trans. Ind. Electron., vol. 59, no.9, pp. 3532-3541, September 2012.

[3] F. Baudart, B. Dehez, E. Matagne, D. Telteu-Nedelcu, P. Alexandre, F. Labrique, " Torque Control Strategy of Polyphase Permanent-Magnet Synchronous Machines With Minimal Controller Reconfiguration Under Open-Circuit Fault of One Phase," IEEE Trans. Ind. Electron., vol. 59, no.6, pp. 2632-2644, june 2012.

[4] M. Villani , M. Tursini , G. Fabri and L. Castellini "High reliability permanent magnet brushless motor drive for aircraft application", IEEE Trans. Ind. Electron., vol. 59, no. 5, pp.2073 -2081 2012.

[5] T. J. dos Santos Moraes, N. K. Nguyen, F. Meinguet, E. Semail, " Fault tolerant dual-motor drives : sinzing of power electronic, ", in Proc. 17th Conference on Power Electronics and Applications, September 2015, Geneva, Swizerland,

[6] T. J. dos Santos Moraes, N. K. Nguyen, F. Meinguet, E. Semail," A comparative study of two fault-tolerant dual-motor drive topologies under short circuit inverter switch fault," IEEE International Symposium on Industrial Electronics, pp. 1490-1495, June 2015, Rio de Janeiro, Brazil.

[7] L. Bin, S. K. Sharma, "A literature review of IGBT fault Diagnostic and protection methods for power inverters," IEEE Trans Indus. Appl., vol.45, no.5, pp.1770-1777, 2009.

[8] R. A. Hanna, S. Prabhu, "Medium-voltage adjustable-speed drives users' and manufactures' experiences," IEEE Trans. Indus. Appl.,vol.33, no.6, pp. 1407-1415, 1997.

[9] X. Kestelyn, E. Semail, "A Vectorial Approach for Generation of Optimal Current References for Multiphase Permanent-Magnet Synchronous Machines in Real Time," IEEE Trans. Ind. Electron., vol.58, no.11, pp.5057-5065, 2011.

[10] X. Kestelyn, E. Semail, "Multiphase Voltage Source Inverters" chap 8 in book "Static Converters", ISBN. 978-1-84821-195-7. ISTE Ltd and John Wiley \& Sons Inc, mars 2011, 27 pages.

[11] X. Kestelyn, E. Semail , "Vectorial Modeling and Control of Multiphase Machines with Non-salient Poles Supplied by an Inverter", Chap7 in book " Control of Non-conventional Synchronous Motors", ISTE Ltd and John Wiley \& Sons Inc, 2012, 44 pages

[12] E. Levi, "Multiphase electric machines for variable-speed applications," IEEE Trans. on Ind. Electron., vol. 55, no. 5, pp. 1893-1909, 2008.

[13] F. Barrero, M. J. Duran, "RecentAdvances in the Design, Modeling and Control of Multiphase Machines », Part 1 and 2, IEEE Trans. Ind. Electron., vol..., no.99, 2015.

[14] H. Guzman, M.J. Duran,F. Barrero, B.Bogado,S. Toral, "Speed Control of Five-Phase Induction Motors With Integrated Open-Phase Fault Operation Using Model-Based Predictive Current Control Techniques," IEEE Trans. Indus. Electron., vol.61, no.9, pp.4474-4484, Sept. 2014.

[15] A.Mohammadpour, L.Parsa, « Global Fault-Tolerant Control Technique for Multiphase Permanent-Magnet Machines, IEEE Trans. Indus. Appl. , vol.51, no.1, pp.178-186, Jan.-Feb. 2015.

[16] N. K. Nguyen, F. Meinguet, E. Semail, X. Kestelyn, "Fault-tolerant operation of an open-end winding five-phase PMSM drive with shortCircuit inverter fault,"IEEE Trans. Ind. Electron., to be published, 2015. 